\title{
Somnofluoroscopy, computed tomography, and cephalometry in the assessment of the airway in obstructive sleep apnoea
}

\author{
J L Pepin, G Ferretti, D Veale, P Romand, M Coulomb, C Brambilla, P A Lévy
}

\begin{abstract}
Background Assessments of the upper airways in patients with the obstructive sleep apnoea syndrome are usually carried out on awake patients who are upright. The dynamics of the airway in a patient who is asleep and lying down may be different.
\end{abstract}

Methods Somnofluoroscopy, computed tomography of the upper airway, and cephalometry were carried out in 11 patients with the obstructive sleep apnoea syndrome (10 male; mean (SD) age 53 (10) years) to examine the airway while they were awake and asleep.

Results At somnofluoroscopy 10 patients were in stage 2 sleep and only one in REM sleep. At least five obstructive events were visualised by lateral fluoroscopy in each patient. Imaging allowed observation of the dynamics of airway collapse, which began in the oropharynx in all cases, progressing to the hypopharynx in 10 cases and to the laryngopharynx in five. At fluoroscopy the soft palate was seen to hook up during airway occlusion in 10 patients, thereby increasing its cross sectional area. It was then sucked down into the hypopharynx. Somnofluoroscopic and cephalometric findings agreed, eight of the 10 patients with hypopharyngeal collapse shown by somnofluoroscopy having an inferiorly placed hyoid bone according to cephalometry (distance from the mandibular plane to the hyoid bone (MP-H distance) increased); the one patient with no hypopharyngeal collapse had a normal MP-H. By contrast, six of the 11 patients had a normal or supranormal hypopharyngeal cross sectional area of the airway on the computed tomogram. Conclusions Somnofiuoroscopy allows examination of the dynamics of airway closure in this disorder and shows the important role of the soft palate in acting as a plug in the oropharynx. Dynamic studies are required to determine the pattern of pharyngeal obstruction in obstructive sleep apnoea.

Patients with the obstructive sleep apnoea syndrome have recurrent cessation of breathing during sleep as a result of collapse of the pharyngeal airway. ${ }^{1}$ Many studies have as- sessed the upper airway in patients by various techniques, including cephalometry, ${ }^{2}$ computed tomography, ${ }^{3}$ cine computed tomography, ${ }^{4}$ fluoroscopy, ${ }^{5}$ acoustic reflectance, ${ }^{6}$ and fibreoptic pharyngoscopy. ${ }^{7}$ These techniques, however, are usually applied to awake or upright patients, where the mechanisms controlling upper airway patency may be different from the dynamics of obstruction in a sleeping patient who is lying down. ${ }^{8}$ Among the mechanisms postulated in the generation of airway collapse are anatomical narrowing of the airway, ${ }^{910}$ increased pharyngeal compliance,${ }^{11}$ increased upstream resistance with a narrowed nasal airway, ${ }^{12}$ and incoordination of the diaphragm and upper airway dilator muscle activation at the onset of inspiration. ${ }^{13}$ Somnofluoroscopy, where the pharyngeal airway is visualised while the patient is asleep (without sedation) with monitoring of sleep stage and airflow, may provide information on the dynamic function of the upper airway and the level of occlusion during sleep. A clear description of the sequence of events occurring before, during, and after an apnoeic event may help to elucidate some of the mechanisms.

We have assessed upper airway dynamics during spontaneous apnoeic events in patients with obstructive sleep apnoea, using somnofluoroscopy to examine obstructive events during sleep proved by electroencephalography. We have performed cephalometry and computed tomography in the same patients, to see if static techniques performed while the patient is awake can give useful information about the level of airway occlusion during sleep.

\section{Methods}

PATIENTS

Eighteen patients referred for assessment of sleep related breathing problems and with hypersomnolence were recruited to the study, which was approved by the hospital ethical committee. The patients were deprived of sleep on the night before the imaging study by being fully woken by the nursing staff every hour. Three patients, one of whom did not have sleep deprivation the night before, did not sleep for a sufficiently long time in the fluoroscopy suite. These patients reported the least hypersomnolence. One patient did not have apnoeic events in the suite. Two patients did not complete the protocol and one had 
central sleep apnoea. Thus 11 patients (10 male) successfully completed the study.

\section{SLEEP STUDIES \\ All night polysomnography}

The patients underwent one night of monitoring, in the week before the somnofluoroscopy, so that the diagnosis could be established and the amount of breathing disturbance quantified. The electroencephalogram (EEG; with electrode positions $\mathrm{C} 3 / \mathrm{A} 2-\mathrm{C} 4 / \mathrm{A} 1-\mathrm{CZ} / \mathrm{O} 1$ of the international 10-20 electrode placement system), electro-oculogram (EOG), chin electromyogram (EMG), and electrocardiogram (ECG; modified V2 lead) were recorded continuously on a ECEM polygraph (Vickers Ltd, Marne La Vallée, France). Respiration was monitored with an uncalibrated inductive respiratory plethysmograph. Airflow was measured semiquantitatively by summing the

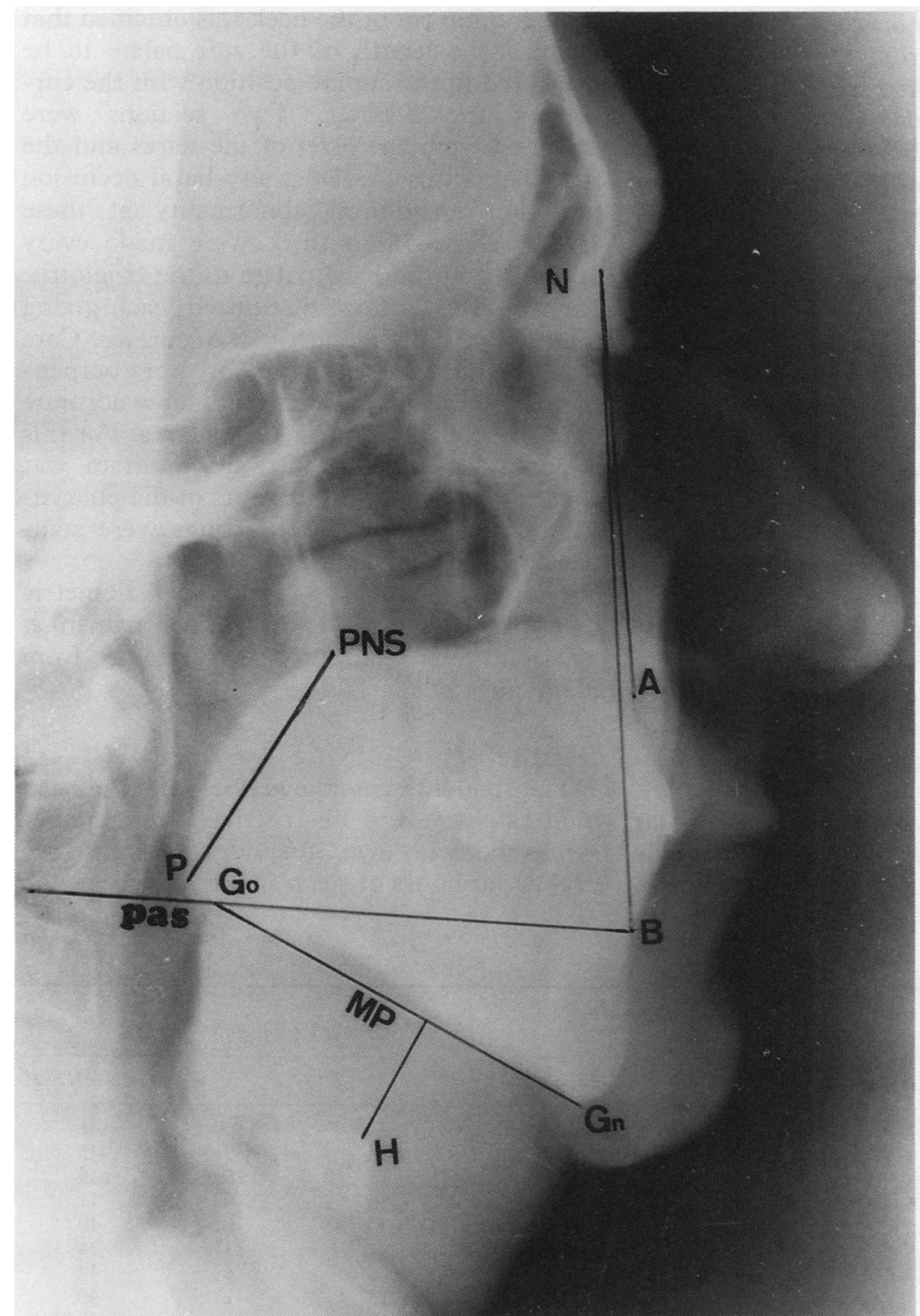

Figure 1 Cephalometry: A-subspinale: deepest point on the premaxillary outer contour between anterior nasal spine and central incisor; $B$-supramentale: deepest point on the outer mandibular contour between mandibular incisor and pogonion; $\mathrm{N}$-nasion: the most anterior point of the nasal floor; $\mathrm{H}$-the most anterior-superior point on the body of the hyoid bone; $P$-tip of the soft palate; Go-gonion: the most posterior-inferior point on the convexity of the angle of the mandible; $G n$-gnathion: the most inferior point in the contour of the chin; MP-mandibular plane, constructed from the gnathion through the gonion; PNS-posterior nasal spine: the most posterior part of the contour of the hard palate; $P A S$-posterior airway space. results of buccal and nasal thermistors, and oxygen saturation $\left(\mathrm{SaO}_{2}\right)$ was measured with a Biox-Ohmeda 3700 oximeter.

The polysomnogram was scored manually according to standard criteria. ${ }^{14}$ Episodes of apnoea were defined as complete cessation of airflow for 10 seconds or more and hypopnoea as a greater than $50 \%$ decrease in oronasal airflow lasting for at least 10 seconds. Apnoeahypopnoea events were classified as central, obstructive, or mixed according to whether and to what extent breathing efforts were present. The obstructive sleep apnoea syndrome was defined by the respiratory disturbance index (number of episodes of apnoea or hypopnoea per hour of sleep). ${ }^{15}$

\section{Somnofluoroscopy with video recording}

Fluoroscopy of the upper airway was performed during a nap at the end of the morning, the patient having been deprived of sleep during the previous night by being woken up fully by the nursing staff every hour. No sedatives were administered to the patient. Polysomnography was performed during the nap.

During the fluoroscopic examination the patient slept in the supine position on a CGR DG 200 angiographic table with the head supported on a pillow. The fluoroscope arm was placed in the horizontal position and centred on the pharynx to obtain a lateral projection of the upper airway. A window size of $16 \mathrm{~cm}$ allowed visualisation of the hard palate, upper cervical spine, soft palate, oropharyngeal soft tissues, and hyoid bone. The fluoroscopic images were transmitted to a UMATIC video recorder for later analysis. A preliminary image was recorded for 30 seconds while the patient was awake. Then the lights were turned out and the patient was allowed to fall asleep, and polysomnographic recording was started. When adequate recordings had been obtained, we allowed the patient to continue to sleep to see whether he developed REM sleep.

Fluoroscopy was performed by a radiologist (GF) while a respiratory physician experienced in polysomnography (JLP or PL) recorded the sleep measures. When the patient had recurrent episodes of apnoea a fluoroscopic recording was made from the end of one event so that the next event could be recorded in its entirety. Five episodes of obstructive apnoea were recorded, giving a total duration of fluoroscopy for each patient of less than three minutes. Each minute of fluoroscopy gave $1 \cdot 2$ $m G y$ of radiation. The polygraphic record was marked to ensure that the fluoroscopic image on the video and the polygraphic event reviewed were the same. Digital subtraction images from the fluoroscopy were obtained for hard copy.

The video recordings of the fluoroscopic examinations were examined and scored independently by three observers (GF, PL, JLP). The records were analysed with close study of the following: area where obstruction of the airway started, extent of the collapse, and morphology of this collapse. The effect of 
the Müller manoeuvre (a maximal inspiration against an occluded airway) was also examined. Inspiratory pressure was not measured as further instrumentation of this kind was likèly to reduce the possibility of sleep and interfere with responses in the airway.

\section{STUDIES PERFORMED ON PATIENTS WHILE AWAKE Cephalometry (fig 1)}

Lateral cephalometric radiographs were obtained by the technique described by Riley et $a .^{2}$ Briefly, the patient was seated with his head in a neutral position, with the gaze parallel to the floor and the teeth together. The $x$ ray plate was placed next to the left side of the face and the cone $1.5 \mathrm{~m}$ from the patient. Exposures were taken with the patient remaining still while slowly exhaling a moderately deep breath. Each study gave 4.7 $\mathrm{mGy}$ of radiation to the skin. The following measurements were made from the radiograph (as described by Riley $e t$ al $^{2}$ ):

$1 M P-H$ distance From the mandibular plane (a plane constructed from the gnathion (Gn) through the gonion (Go)) to the hyoid bone $(\mathrm{H})$-see fig 1 . The normal mean (SD) value is 15.4 (3) $\mathrm{mm}$ and in the obstructive sleep apnoea syndrome a value greater than $24 \mathrm{~mm}$ correlates with a high apnoea plus hypopnoea index independently of the body mass index. ${ }^{16}$

$2 P A S$ The posterior airway space, with normal dimensions of 11 (2) $\mathrm{mm}$. A reduction in size to $5 \mathrm{~mm}$ or less in patients with obstructive sleep apnoea syndrome correlates with a high apnoea plus hypopnoea index independently of body mass index. ${ }^{16}$

$3 P N S-P$ From the posterior nasal spine to the tip of the palate. This gives a measure of the length of the soft palate and has a normal mean (SD) of 34 (6) $\mathrm{mm}$.

$4 A N B$ angle From subspinale (A; deepest point on the premaxillary outer contour between the anterior nasal spine and central incisor) to the nasion (N) and to the supramentale (B; deepest point on the outer mandibular contour between the mandibular incisor and the pogonion). This angle measures discrepencies between the mandible and the maxilla, so patients with a significant increase in the ANB angle (normal $2^{\circ}$ ) generally have a normal maxilla but a mandibular deficiency.

\section{Computed tomography}

The purpose of computed tomography was to measure the luminal area of the airway at the level of the nasopharynx, oropharynx, and hypopharynx to see whether narrowing could be observed at more than one level. Scans were performed on a CE 12000 CGR computed tomographic scanner with a 3.4 second scan time. Patients were closely observed to ensure that they remained awake throughout the procedure and did not swallow during imaging. Scanning was performed during quiet breathing. The subjects were placed in the supine position on the scanning table, with the neck placed in a neutral position midway between flexion and extension. A lateral tomographic cut of the neck was obtained that enabled the length of the soft palate to be measured in the supine position with the cursor of the scanner. Two sections were obtained from the level of the nares and the maxillary sinus to detect any nasal occlusion or other anatomical abnormality at these levels. Slices $5 \mathrm{~mm}$ thick were made every $10 \mathrm{~mm}$ from the hard palate to the epiglottis. Eight to 10 slices were required, each giving $10 \mathrm{mGy}$ of radiation at the skin surface. Care was taken to ensure that all cuts were perpendicular to the airway lumen to allow accurate assessment of the cross sectional area. For this purpose, an integral software program was used to determine the contours of the pharyngal lumen. The window settings were standardised for all the patients.

Normal ranges for cephalometric measurements were taken from Partinen et $a l^{16}$ and for computed tomograms from Haponik et al. ${ }^{17}$

\section{Results}

Eleven patients completed the study; all had moderately severe obstructive sleep apnoea syndrome, with over 30 apnoea or hypopnoea events per hours of sleep (table). Three of the

Details of the patients

\begin{tabular}{|c|c|c|c|c|c|c|c|c|c|}
\hline \multirow{2}{*}{$\begin{array}{l}\text { Patient } \\
\text { No }\end{array}$} & \multirow[b]{2}{*}{ Age (y) } & \multirow[b]{2}{*}{$B M I\left(\mathrm{~kg} / \mathrm{m}^{2}\right)$} & \multirow[b]{2}{*}{$R D I(n / h)$} & \multicolumn{3}{|c|}{$\begin{array}{l}\text { Computed tomographic pharyngeal } \\
C S A\left(\mathrm{~cm}^{2}\right)\end{array}$} & \multicolumn{3}{|c|}{ Cephalometric values ( $\mathrm{mm}$ ) } \\
\hline & & & & Rhino & Oro & Hypo & $M P-H$ & $P A S$ & $P N S-P$ \\
\hline 1 & 35 & 27 & 35 & $1 \cdot 70$ & 0.23 & $1 \cdot 14$ & 27 & 10 & 41 \\
\hline 2 & 61 & 29 & 55 & $4 \cdot 35$ & 0.68 & 1.29 & 32 & 7 & 45 \\
\hline 3 & 59 & 41 & 50 & $3 \cdot 80$ & 0.45 & $2 \cdot 28$ & 15 & 10 & 49 \\
\hline 4 & 51 & 28 & 51 & $5 \cdot 00$ & 0.73 & $1 \cdot 40$ & 20 & 9 & 41 \\
\hline 5 & 43 & 37 & 97 & $2 \cdot 05$ & 0.24 & 0.36 & 30 & 9 & 40 \\
\hline 6 & 55 & 24 & 70 & 5.80 & 0.48 & $4 \cdot 14$ & 21 & 11 & 44 \\
\hline 7 & 45 & 27 & 86 & & 0.63 & 0.78 & 28 & 6 & 44 \\
\hline 8 & 56 & 53 & 70 & $4 \cdot 17$ & 1.62 & $3 \cdot 36$ & 13 & 12 & 40 \\
\hline 9 & 65 & 34 & 80 & 3.60 & 0.58 & $5 \cdot 34$ & 15 & 10 & 45 \\
\hline 10 & 65 & 35 & 77 & 4.00 & 1.60 & 8.00 & 29 & 18 & 52 \\
\hline 11 & 44 & 32 & 50 & $5 \cdot 43$ & 0.22 & $2 \cdot 12$ & 25 & 6 & 43 \\
\hline Mean & 53 & 33 & 65 & 4 & 0.68 & $2 \cdot 75$ & 23 & 10 & 44 \\
\hline SD & 10 & 8 & 19 & $1 \cdot 3$ & 0.49 & $2 \cdot 31$ & 7 & 3 & 4 \\
\hline
\end{tabular}

BMI - body mass index; CSA - cross sectional area; RDI-respiratory disturbance index (number of apnoeic plus hypopnoeic episodes per hour slept) rhino-rhinopharynx; oro-oropharynx; hypo-hypopharynx; MP-H-mandibular plane to hyoid bone distance; PAS-posterior airway space; PNS-P-length of soft palate. 
patients had documented chronic obstructive lung disease with a vital capacity (VC) of 63$76 \%$ predicted and an $\mathrm{FEV}_{1} / \mathrm{VC}$ of $55-67 \%$.

\section{SOMNOFLUOROSCOPY}

The patients fell asleep within 5-30 minutes after the lights had been turned out. All patients reached sleep stages 1 and 2 , but none reached stage 3 or $4 .{ }^{14}$ Only patient 8 had REM sleep, which occurred just before she woke at the end of the examination. Recording of events was started when the patient was in established stage 2 sleep. This was always after at least one hour of sleep. The study was continued for up to three and a half hours (median 2, range $1-3.5$ hours) if necessary for five events to be visualised.

The patients all had episodes of obstructive apnoea that were seen by the staff and recorded on the polysomnogram. These apnoeic episodes were frequent and recurrent in all cases and allowed proper monitoring of at least five episodes at fluoroscopy. Recording was started when the patient was established in a cycle of apnoeic episodes. A characteristic pattern was established progressively for each patient, and was usually established by the fourth apnoea.

\section{Start of collapse and early phase}

In all cases the airway closure began in the oropharynx. It extended progressively downwards to the hypopharynx in 10 cases and further - that is, to the pharyngolarynx - in five cases.

\section{Hyoid bone}

The hyoid bone could be visualised during somnofluoroscopy in all but two patients, who were extremely obese. There was no specific pattern to the hyoid movement, nor did the direction of movement correlate with the cephalometric MP-H distance. The bone was moved upwards, downwards, and posteriorly in equal numbers of patients.

\section{Cervical spine}

The active movements during the apnoeic events "spread" to the cervical spine, which was seen to move forward in seven cases. This movement usually occurred with active jaw movement and this sequence gave us an impressive picture of the patients struggling vigorously against their airway occlusion.

\section{Tongue and soft palate}

In all cases the tongue was seen to move backwards into the posterior oropharynx during apnoea. The uvula was seen to hook posteriorly against the posterior pharyngeal wall in six cases and anteriorly towards the back of the tongue in four cases.

\section{Airway reopening}

As the patient struggled to overcome the airway obstruction the hypopharynx occasionally opened briefly, without any resumption of ventilation before closing again. The actual reopening of the airway was closely examined and found to be sudden in five cases, progressive in five cases, and difficult to define in the remaining case. In the patients with sudden opening of the airway the whole pharynx usually opened as a unit. In four cases the airway reopening started in the hypopharynx and extended progressively upwards. Airway opening was in expiration and usually associated with very active movements of the jaw. These patterns were consistent for each patient and were seen in the five events that were monitored in each case.

\section{Müller manoeuvre}

The Müller manoeuvre, performed while the patient was awake, produced a complete collapse of the airway down to the hypopharynx in only four patients; in three of these somnofluoroscopy showed extension of airway collapse to the laryngopharynx during the inspiratory effort. The pressure generated in each manoeuvre was uncontrolled and thus a lack of airway collapse may merely reflect insufficient negative pressure.

\section{Synthesis}

A wide range of events was seen at somnofluoroscopy. A classical pattern of events occurring during an episode of apnoea was the beginning of airway occlusion in the oropharynx with posterior movement of the tongue. This was followed by suction on the uvula downwards with progression of the occlusion to the hypopharynx. This in turn was associated with hooking of the soft palate with further narrowing of the airway and finally occlusion. The occlusion was associated with active movements of the jaw and cervical spine and hyoid bone as if the patient were choking. The overcoming of the occlusion was usually accompanied by opening of the jaw and occurred either as a sudden event throughout the length of the pharyngeal airway or as a progressive reopening from the hypopharynx.

\section{CEPHALOMETRY}

Only one patient (No 8) had entirely normal cephalometric results; all the other patients had at least one of the four cephalometric measurements outside the normal range (fig 2). The greatest abnormality found by cephalometry was in the measurement of MP-H, eight of the 11 patients having an inferiorly placed hyoid bone (MP-H over $18.4 \mathrm{~mm}$ ). Six of these eigtht had an MP-H greater than $24 \mathrm{~mm}$. Three patients had an inadequate PAS in the upright posture (less than $9 \mathrm{~mm}$ ) and two of these had, in addition, an abnormal length soft palate (PNS-P over $43 \mathrm{~mm}$ ). These three patients all had an RDI of over 50/h. Patient 11 was the only one to show evidence of mandibular deficiency at cephalometry (ANB $4^{\circ}$ ).

\section{COMPUTED TOMOGRAPHY}

Six patients had narrowing of the rhinopharyngeal airway on the computed tomogram, but the most striking finding was that all patients had a substantial reduction in the cross sectional area of the oropharynx in the supine posture (fig 3 ). This was the only computed tomographic abnormality found in two cases. Five patients had a reduced hypopharyngeal 


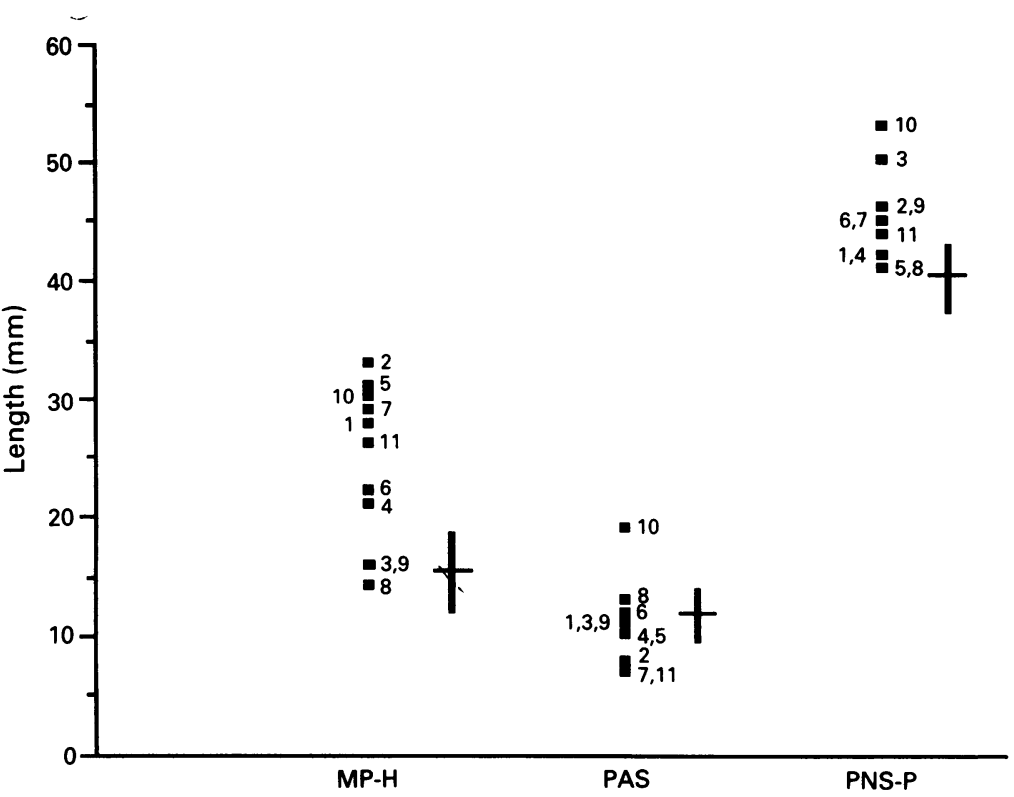

Figure 2 Cephalometric dimensions (in mm) of $M P-H$ (mandibular plane to hyoid bone distance), posterior airway space (PAS), and length of the soft palate (PNS-P). Each numbered dot represents a patient. The horizontal lines show the mean and the bar the range for a normal population.

cross sectional area. Thus two patients (Nos 1 and 5) showed a reduction in cross sectional area throughout the pharynx and seven patients a reduction in cross sectional area in two parts of the pharynx.

\section{COMPARISON OF TECHNIQUES}

Computed tomography was the only method for examining anatomical abnormalities or narrowing of the rhinopharynx. Somnofluoroscopy showed extension of airway collapse to the hypopharynx in all but one patient (No 9). Computed tomography of this area showed no reduction, however, in six of these. Cephalometry, performed on upright patients, showed a reduced posterior airway space in

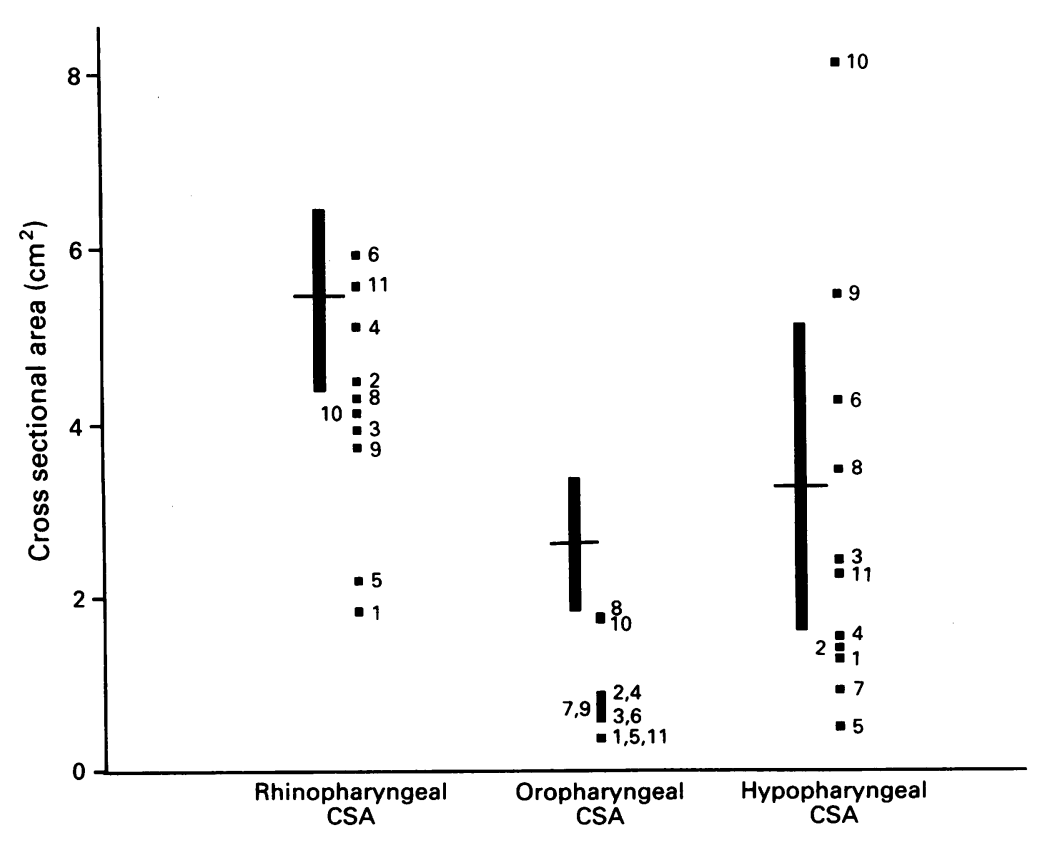

Figure 3 Computed tomographic dimensions (in $\mathrm{cm}^{2}$ ) of rhinopharynx, oropharynx, and hypopharyngeal cross sectional area $(C S A)$. Each numbered dot represents a patient. The horizontal lines show the mean and the bars the range for a normal population. Patient 7 did not have measurement of rhinopharyngeal cross sectional area. three patients only (Nos $2,7,11$ ) and thus disagreed with the findings in the hypopharynx at somnofluoroscopy in seven patients. Eight of the 10 patients with hypopharyngeal closure seen at somnofluoroscopy had an abnormal MP-H with an inferiorly placed hyoid bone. Furthermore, the one patient (No 9) with no hypopharyngeal collapse seen at somnofluoroscopy had a normal MP-H; thus the MP-H measurementsagreed with fluoroscopicfindings in nine of 11 patients. The length of the soft palate in each patient on the computed tomogram was identical to the cephalometric measurements of PNS-P.

\section{Discussion}

We have shown that somnofluoroscopy allows a complete examination of the sequence of events that leads to upper airway collapse in the obstructive sleep apnoea syndrome (fig 4). It is important to anticipate the beginning of an occlusive event as fluoroscopy started when airflow has decreased will miss the beginning of an event. This imaging technique shows that the movements of the soft palate have a crucial role in the final collapse of the airway. Somnofluoroscopy showed collapse of the hypopharynx in all but one case. The discrepancy between the findings of the static and the dynamic examinations emphasises the importance not only of anatomical factors but also of functional determinants of collapse.

Fluoroscopic examination of the airway in the obstructive sleep apnoea syndrome was first described in 1967 in a case report by Schwartz et $a l,{ }^{5}$ and Smith et al in 1978 first described the use of this technique to show the extent and progression of airway collapse. ${ }^{18}$

Suratt et al in 1982 compared fluoroscopy and computed tomography, ${ }^{19}$ using thick barium to help to outline the pharynx, though this may have changed upper airway muscle control. They, like us, found that the narrowest area of the pharynx on the computed tomogram was the area most likely to collapse at fluoroscopy. They described fluttering of the soft palate, which was associated with snoring. Although this consisted of soft palate movement, it is different from the hooking up of this tissue, which just preceded airway collapse in our observations. Suratt et al did not provide a clear description of the sequence of events leading to closure of the airway, which we describe as hooking (leading to oropharyngeal collapse) and plugging (leading to hypopharyngeal collapse). Furthermore, no monitoring of sleep was performed in their study.

Our finding of the hooking up of the soft palate before the complete collapse of the pharynx implies activation of muscles in the soft palate. These inappropriate movements of the soft palate result in an increasing airflow resistance and thus increasing transpharyngeal pressure, which aids airway collapse. ${ }^{12}$ Stauffer et $a^{20}$ examined the morphological changes in uvular tissue from uvulopalatopharyngoplasty and found muscular hypertrophy. They postulated that this may represent an adaptation to increased pharyngeal airflow resistance. They also postulated that the stimulus for muscle 


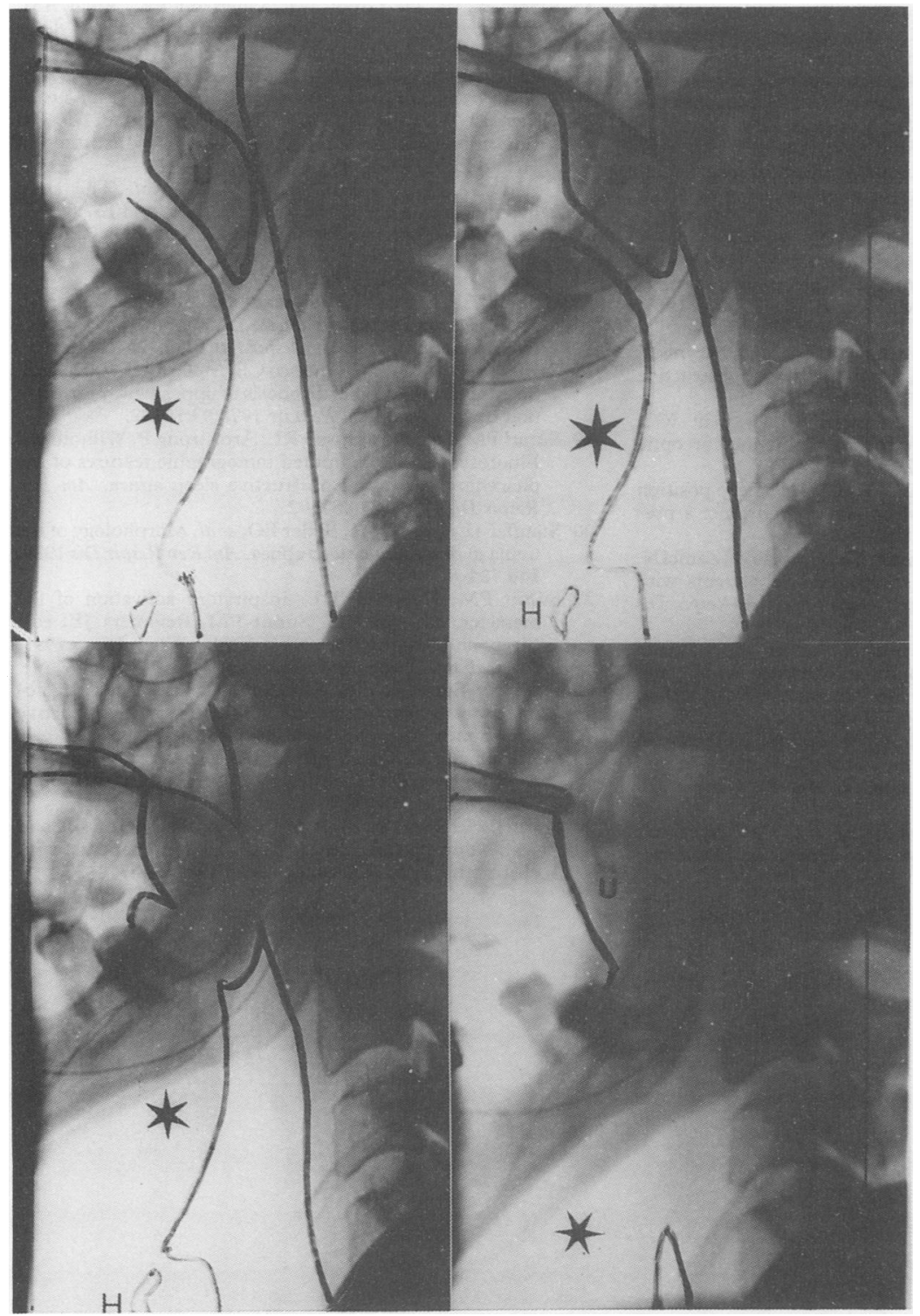

Figure 4 Hard copy of fluoroscopic images in patient 6: Upper panel shows the patent oropharyngeal airway outlined with the large uvula extending down into the lower oropharynx; lower panel shows the hooking forward of the uvula during an occlusive event. U-uvula; H-hyoid bone; ${ }^{\star}$ Hypopharyngeal level.

hypertrophy might be an increased contraction of pharyngeal muscles. Our observation of the hooking of a normal length soft palate may indicate that the increased activity of soft palate muscles is of crucial importance in producing upper airway collapse and may even precede major morphological changes in the soft palate.

Somnofluoroscopy allowed us to visualise events outside the pharyngeal airway occurring during apnoea with movements of the cervical spine and downward movement of the hyoid bone. The jaw movements seen at the end of an apnoeic event is in accordance with the finding of Suratt and Hollowell that the masseter muscle is activated towards the end of an episode of apnoea. ${ }^{21}$ These movements may be important for reopening the upper airway.

Whereas somriofluoroscopy describes the dynamic events occurring in the obstructive sleep apnoea syndrome the static image of cephalometry and computed tomography may show which patients are prone to these developments. Cephalometry showed that most patients did not have a long soft palate or a narrowed posterior airway space, but measurements of MP-H made by cephalometry with the patient upright agreed with our fluoroscopic findings in the hypopharynx in nine patients. This reflects the fact that the position of the hyoid bone has an impact on the tongue shape and posture and affects the patency of the hypopharyngeal airway. ${ }^{22}$ Patient 8 was the only one with entirely normal cephalometric values. This was a massively obese woman who had hypercapnia and severe hypoxia while awake. In women the degree of obesity determines the likelihood of the obstructive sleep apnoea syndrome to a greater and more independent degree than in men, ${ }^{23}$ and this may explain why the static images give no indication of the extent of the collapse in this case.

Computed tomography performed while the patients were awake showed that a large proportion had a reduced rhinopharynx. This may predispose to airway collapse by means of an increase in transpharyngeal pressure even in patients with a normal oropharyngeal cross sectional area as shown by computed tomography. ${ }^{12}$ In this small group of patients, however, the oropharyngeal airway was narrowed in all cases on the computed tomogram. We found, by contrast, hypopharyngeal narrowing in only five of our patients. Thus we would agree with Horner et al that computed tomography during wakefulness does not predict the development of airway occlusion below the soft palate when the patient is asleep. $^{24}$

The crucial question in the clinical assessment of the airway in the obstructive sleep apnoea syndrome is whether the collapse extends to the hypopharynx or not. We cannot be absolutely sure about this unless we examine the patients while they are supine and asleep. Ideally the patient should achieve all stages of sleep, though if complete airway collapse to the hypopharynx occurs in sleep stage 1 or 2 little further clinical information will result from prolonged imaging. Somnofluroscopy best approaches fulfilment of these criteria and from our results it seems logical to perform fluoroscopy in patients with no hypopharyngeal narrowing detected by computed tomography or cephalometry to identify the extension of the collapse. Fluoroscopy in the awake patient would not visualise any of the occlusive events that occur during sleep, but studies are needed in awake patients to be certain that abnormal movements of the soft palate, such as hooking, do not occur while the subject is awake.

In conclusion, we have examined the use of cephalometry, computed tomography, and somnofluoroscopy in the assessment of the airway in the obstructive sleep apnoea syndrome. Somnofluoroscopy allows examination of the dynamics of airway closure in this disorder. This highlights the importance of dynamic studies in determining the pattern of pharyngeal obstruction in the obstructive sleep apnoea syndrome.

This work was supported by grants from ADRAR, Comares, and Universite Joseph Fourier. We thank Catherine Bonnet, chief technician of the sleep laboratory, for technical assistance. $\mathrm{DV}$ is a research associate from the Northern Regional Health Authority, Newcastle upon Tyne, supported by a grant from the Region Rhône-Alpes, Lyon. 
1 Stradling JR. The sleep apnoea syndromes. In: Brewis RAL, Gibson GJ, Geddes DM, eds. Respiratory medicine. London: Bailliere Tindall, 1990:1356-72.

2 Riley R, Guilleminault C, Herran J, Powel N. Cephalometric analyses and flow-volume loops in obstructive sleep apnea patients. Sleep 1983;6:303-11.

3 Bohlman ME, Haponik EF, Smith PL, Allen RP, Bleecker ER, Goldman SM. CT demonstration of pharyngeal narrowing in adult obstructive sleep apnea. AJR 1983; $140: 543-8$.

4 Ell SR, Jolles H, Galvin JR. Cine CT demonstration of nonfixed upper airway obstruction. AJR 1986;146:669-77.

5 Schwartz BA, Escande JP. Etude cinéradiographique de la respiration hypnique pickwickienne. Rev Neurol 1967; 87:677-8.

6 Bradley TD, Brown IG, Grossman RF, et al. Pharyngeal size in snorers, nonsnorers, and patients with obstructive sleep apnea. $N$ Engl J Med 1986;315:1327-31.

7 Guilleminault C, Hill MW, Simmons FB, Dement WC. Obstructive sleep apnea: electromyographic and fibreoptic studies. Exp Neurol 1978;62:48-67.

8 Cartwright RD, Lloyd S, Lilie J, Kravitz H. Sleep position training as treatment for sleep apnea syndrome: a preliminary study. Sleep 1985;8:87-94.

9 Rivlin J, Hoffstein V, Kalbfleisch J, McNicholas W, ZamelN, Bryan AC. Upper airway morphology in patients with idiopathic obstructive sleep apnoea. Am Rev Respir Dis 1984;129:355-60.

10 Shepard JW, Thawley SE. Evaluation of the upper airway by computerized tomography in patients undergoing uvulopalatopharyngoplasty for obstructive sleep apnea. Am Rev Respir Dis 1989;140:711-6.

11 Brown IG, Bradley TD, Phillipson EA, Zamel N, Hoffstein $\mathrm{V}$. Pharyngeal compliance in snoring subjects with and without obstructive sleep apnoea. Am Rev Respir Dis 1985;132:211-5.

12 Stauffer JL, Zwillich CW, Cadieux RJ, et al. Pharyngeal size and resistance in obstructive sleep apnea. Am Rev Respir Dis 1987;136:623-7.
13 Remmers JE, De Groot WJ, Sauerland EK, Anch AM. Pathogenesis of upper airway occlusion during sleep. $J$ Appl Physiol 1978;44:931-8.

14 Rechtschaffen A, Kales A A manual of standardized terminology, techniques and scoring system for sleep stages of human subjects. Washington, DC: US Department of Health, Education and Welfare, 1968. (National Institutes of Health Publication No (NIH) 204.)

15 Gould GA, Whyte KF, Rhind GB, et al. The sleep hypopnoea syndrome. Am Rev Respir Dis 1988;137:895-8.

16 Partinen M, Guilleminault C, Quera-Salva MA, Jamieson A. Obstructive sleep apnea and cephalometric roentgenograms. Chest 1988;93:1199-205.

17 Haponik EF, Smith PL, Bohlman ME, Allen RP, Goldman SM, Bleecker ER. Computerized tomography in obstructive sleep apnea. Am Rev Respir Dis 1983;127:221-6.

18 Smith TH, Baska RE, Francisco CB, McGray GM, Kunz S. Sleep apnea syndrome: diagnosis of upper airway obstruction by fluoroscopy. J Pediatr 1978;93:891-2.

19 Suratt PM, Dee P, Atkinson RL, Armstrong P, Wilhoit SC. Fluoroscopic and computed tomographic features of the pharyngeal airway in obstructive sleep apnea. Am Rev Respir Dis 1983;127:487-92.

20 Stauffer JL, Buick MK, Bixler EO, et al. Morphology of the uvula in obstructive sleep apnea. Am Rev Respir Dis 1989; uvula in obstr.

21 Suratt PM, Hollowell DE. Inspiratory activation of the masseter. In: Issa FG, Suratt PM, Remmers JE, eds. Sleep and respiration. New York: Wiley-Liss, 1991. Clinical and Biological Research vol 345.

22 De Berry-Borowiecki B, Kukwa A, Blanks RHI. Cephalometric analysis for diagnosis and treatment of obstructive sleep apnea. Laryngoscope 1988;98:226-34.

23 Guilleminault C, Quera-Salva MA, Partinen M, Jamieson A. Women and the obstructive sleep apnea syndrome. Chest 1988;93:104-9.

24 Horner RL, Shea SA, McIvor J, Guz A. Pharyngeal size and shape during wakefulness and sleep in patients with obstructive sleep apnoea. $Q J$ Med 1989;268:719-35. 